\title{
Coulisses
}

Revue de théâtre

\section{The Rocky Horror Show. Don't dream, be it ! (Ne rêvez pas, existez !)}

Rédaction

\section{(2) OpenEdition}

1 Journals

Édition électronique

URL : http://journals.openedition.org/coulisses/1656

DOI : $10.4000 /$ coulisses. 1656

ISSN : 2546-9460

Éditeur

Presses universitaires de Franche-Comté

\section{Édition imprimée}

Date de publication : 1 février 1991

Pagination : 60-61

ISSN : 1150-594X

\section{Référence électronique}

Rédaction, "The Rocky Horror Show. Don't dream, be it! (Ne rêvez pas, existez !) ", Coulisses [En ligne], 3 | Hiver 1991, mis en ligne le 04 juillet 2017, consulté le 25 octobre 2019. URL : http:// journals.openedition.org/coulisses/1656; DOI : 10.4000/coulisses.1656

Ce document a été généré automatiquement le 25 octobre 2019.

Coulisses 


\section{The Rocky Horror Show. Don't dream, be it ! (Ne rêvez pas, existez !)}

\section{Rédaction}

Jeunes fiancés Brad et Janet, trouvent refuge par une nuit d'orage dans le Château de Frankenstein en train de mettre au point sa créature: Rocky. Livrés à eux-mêmes, nos deux héros vont vivre des moments horrifiques et des expériences les plus folles, au cours de cette nuit de cauchemar...

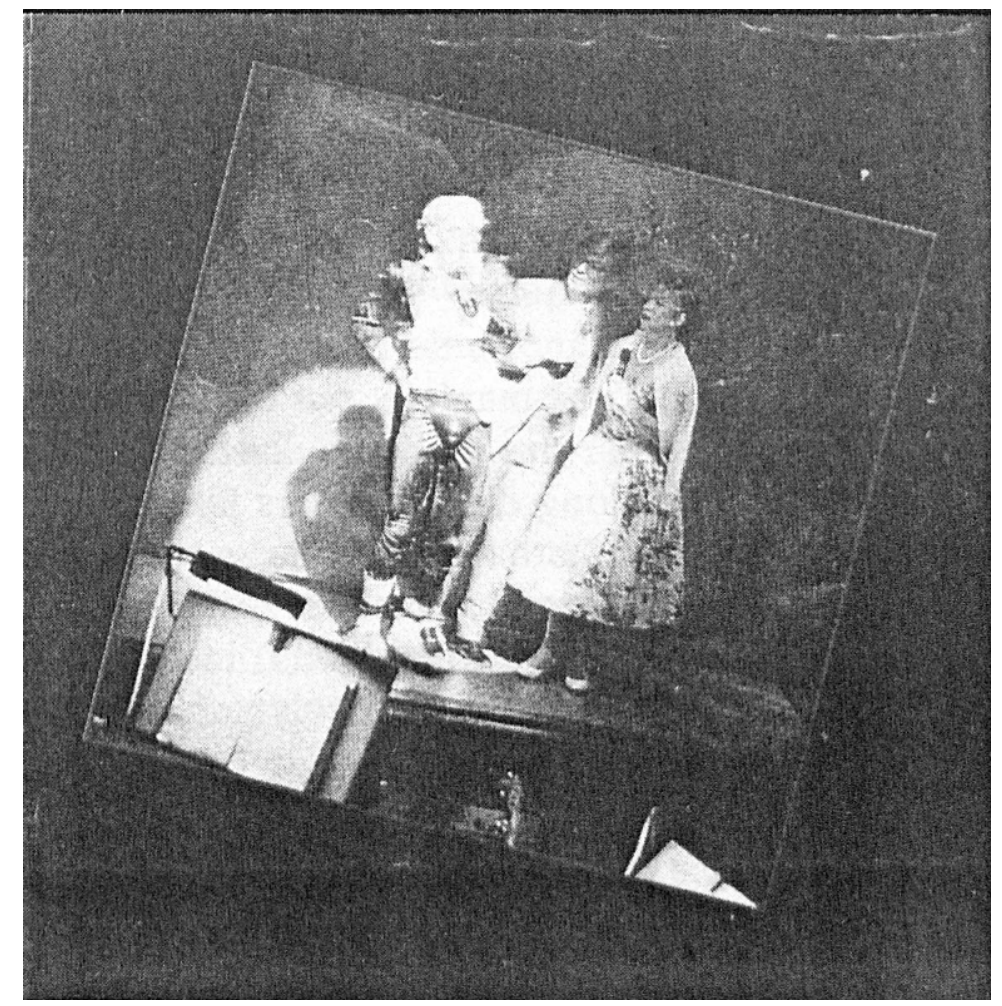

2 Spectacle profondément original, parodie outrancière des films d'horreur et de science fiction des années soixante-dix, le Rocky Horror Show est une délirante comédie musicale rock, dont la galerie des personnages à été largement inspirée des séries B miteuses à 
petit budget Alors qu'il est au chômage, Richard O'Brien lui donne naissance, en écrivant l'histoire et composant chansons et musique. Créée en 1973 à Londres,son oeuvre, à partir de laquelle a été réalisé le célèbre film The Rocky Horror Picture Show, continue à être jouée à travers le monde, avec le même succès. Comte Dracula en personne, longues capes noires et chevelures crêpées, ou de tenue dernier-cri sado-masochiste, porte-jaretelles, bas-résilles ou autres sous-vêtement de cuir, se chargent de mener tel spectateur sur scène e de l'asseoir sur la chaise réservée au conteur, de déposer un gros "smack » dégoulinant de rouge à lèvres sur le crâne d'un bedonnant quinquagénaire dégarni, de s'approcher à pas de loups pour vous souffler par surprise dans l'oreille ou d'explorer le contenu de votre sac à main., en un mot, de faire frémir l'assistance...

6 La représentation commence. Le conteur fait son entrée, et, dans un français approximatif marqué par un accent fortement prononcé, il entreprend la narration, sous les sifflements et quolibets des fans... et ainsi, tout au long de la pièce. Ces derniers, bientôt imités par l'ensemble du public, animeront la salle (lancer de riz lors de la célébration du mariage, trombes d'eau durant l'orage, flammes des briquets pendant la chanson intitulée There is no light... ou dialogueront avec les comédiens. Alors que Rif-Raf, macabre serviteur de Frank'n entre en scène, il est de coutume de crier : « Say Hello, Rif-Raf ! », et ce dernier de lancer : « Good evening ! Or, ce soir-là, méfiez-vous des amis l'assistance clame: «Say good evening Rif-Raf !»... Présence d'esprit oblige, l'acteur tonne « Bonsoaâââr ! »

7 Improvisations, clins d'oeil (Frankenstein, Superman, Dracula...) et « réactualisations » du texte au moyen de diverses allusions, aussi bien à la publicité, ainsi, Rocky, caressant la blonde chevelure de Janet, lui demande-t-il : « Have you got any St-st-studio line? ", qu'à des tubes, Frank'n stoppe, par exemple, chanteurs et danseurs en pleine évolution en lançant. "Frankie says: Relax!», ne constituent pas les seules modifications opérées sur la pièce, qui a, pour l'occasion, fait l'objet d'un lifting teinté de « French fashion ». On y entendra ainsi des interjections fort inattendues telles que Joe le Taxi ", Rocky insulter Frank'n en français, avec, à la plus grande surprise de tous, un naturel stupéfiant (l'acteur est français), des airs de French-Cancan, et, pour finir, les dernières paroles de Frank'n ne sont-elles pas : « Non, je ne regrette rien!»?

Ainsi, séquences de type grande revue au Crazy Horse, situations de Vaudeville dignes de Feydeau, scènes inspirées par films d'horreur, Frankenstein, Dracula... ou de sciencefiction, Superman, le temps d'un remarquable show-laser, entrecoupées d'allusions, d'interruptions et interjections provenant du public, se succèdent à un rythme endiablé, à la plus grande joie des spectateurs, qui, quelque peu étonnés ou timorés en 
début de représentation, se laissent bientôt entraîner dans ce tourbillon délirant, frappant dans leurs mains, dansant et chantant...

9 Que la fête continue!

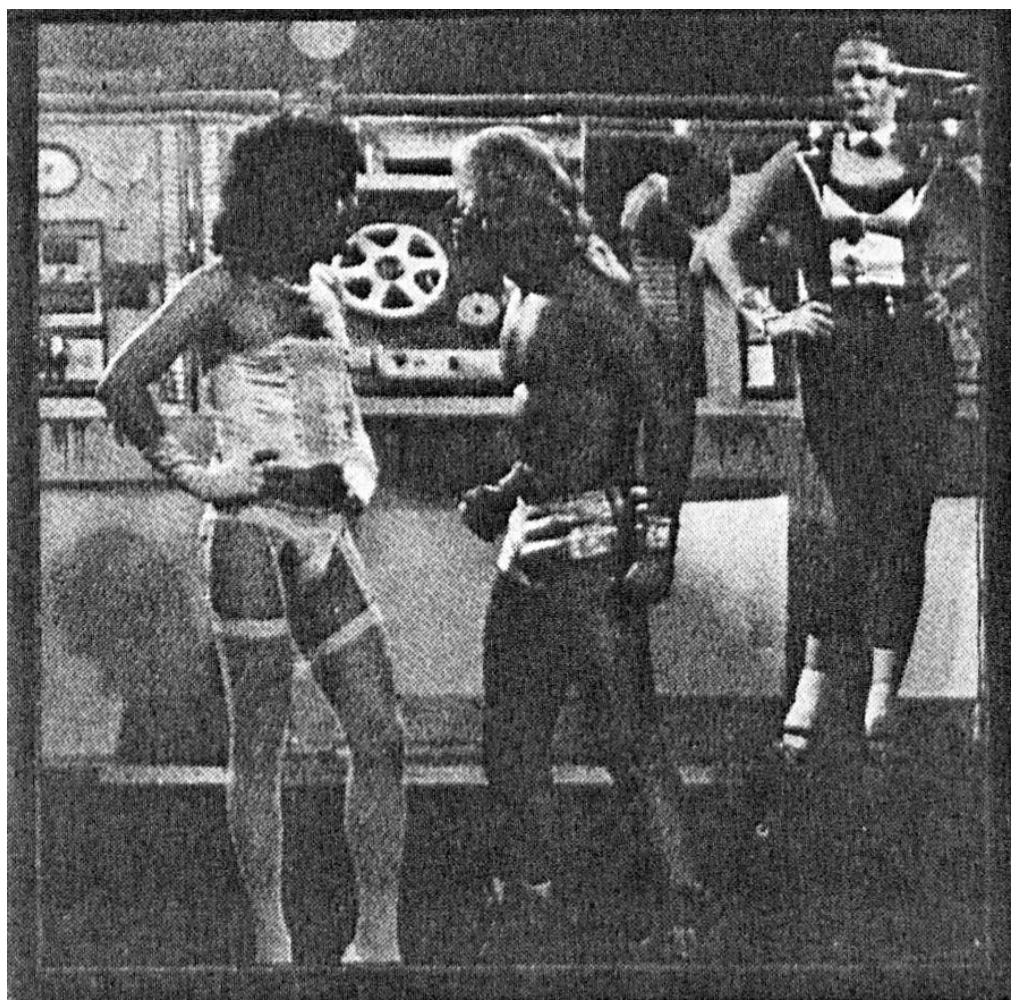

